\title{
Imaginario colectivo en los Estados Nacionales del siglo XIX: realidades, tramas históricas e invenciones literarias y artísticas. El caso de Giuseppe Garibaldi*
}

\author{
Collective imaginary in the National States of the XIX century: \\ realities, historical plots and literary and artistic inventions. \\ The case of Giuseppe Garibaldi. \\ Luisa Consuelo Soler L \\ Facultad de Estudios Sociales y Humanísticos \\ Universidad Autónoma de Chile \\ lsolerl@uautonoma.cl \\ Noemí Cinelli \\ Departamento de Historia del Arte y Filosofía \\ Universidad de La Laguna-España \\ ncinelli@uautonoma.cl
}

\section{Resumen}

El objetivo general es observar el pasado a través de la evolución epistemológica disciplinar de la Historia y el Arte para articularlo a las nociones de realidades en el contexto de los Estados Nacionales. Específicamente, se interpreta cómo han sido descritos literaria y artísticamente los relatos, tomando como referente un caso histórico con resonancia latinoamericana y continental. Se plantea que las tramas históricas y las invenciones literarias artísticas son formas de conocimiento socialmente situados dentro de un sistema de autoridad vigente facilitando cimentar relatos e imaginarios en el colectivo. Metodológicamente se emplea la heurística y hermenéutica para tratar textos históricos; para las obras artísticas el método preiconográfico-iconográfico-iconológico panofskyano

Palabras clave: Imaginarios colectivos; realidades; tramas históricas; literarias; artísticas; Estados Nacionales.

\section{Abstract}

The general objective is to observe the past through the disciplinary epistemological evolution of History

\footnotetext{
*Investigación realizada con financiamiento de la Agencia Nacional de Investigación y Desarrollo (ANID- Chile) en el marco del proyecto Fondecyt Regular 1201032 “Ecos desde el belpaese al exuberante Chile. Relaciones artísticas ítalo-chilenas. Ámbito pintura (1836-1910) cuya investigadora responsable es la Dra. Noemí Cinelli.
} 
and Art to articulate it to the notions of realities in the context of the National States. Specifically, it is interpreted how the stories have been described literarily and artistically, taking as a reference a historical case with Latin American and continental resonance. It is argued that historical plots and artistic literary inventions are forms of knowledge socially located within a system of current authority, facilitating the foundation of stories and imaginaries in the collective. Methodologically, heuristics and hermeneutics are used to treat historical texts; for artistic works the panofskyan pre-iconographic-iconographic-iconological method.

Key words: Collective imaginaries; realities; historical plots; literary; artistic; National States

Recibido: 07 de marzo $2021 \cdot$ Aceptado: 08 de julio 2021

\section{Introducción}

En la modernidad, el conocimiento ya no se limitó a saber qué es la realidad. La pregunta se amplió a quiénes la construyen, qué significa y cuáles son sus significados en el colectivo social. Lo mismo sucedió en la nueva historia de las ideas, que extendió su análisis de las grandes ideas y de sus creadores a las visiones del mundo compartido, a su difusión mediática y su consolidación social (Becker, 2016: 125).

En este sentido, resulta particularmente relevante en este artículo, analizar cómo los saberes disciplinares fueron alimentando a los imaginarios colectivos (en este caso a las sociedades del siglo XIX), fijándonos en primer lugar en los posicionamientos epistémicos asociados a la noción de realidad en sus diversas interpretaciones. Específicamente se busca observar el pasado a través de la evolución epistemológica disciplinar de la Historia y el Arte, en su relación con ciertas realidades instaladas en el imaginario colectivo. Es pertinente considerar que en la construcción de los Estados Nacionales prevaleció la idea de hacer creer "ciertas realidades" empleando relatos organizados y respaldados por discursos del saber.

Como línea base argumental, planteamos que las tramas históricas y las invenciones literarias artísticas son formas de conocimiento socialmente situados dentro de un sistema de autoridad vigente, facilitando cimentar relatos e imaginarios en el colectivo social. Estas ideas se nutren de las aportaciones teóricas de Ricoeur, quien con su operación epistemológica nos alertó sobre la importancia de atender el sistema de autoridad vigente y su relación con la realidad.[1] A su vez nutren las reflexiones epistemológicas los trabajos de Galassi y García; Certeau, Luhmann, Mendiola, Becker, entre otros, quienes nos facilitan abstracciones teórico-epistemológicas sobre cómo una determinada realidad se objetiva en función del momento-circunstancia, del evento-acontecimiento y de la ideología; cuestiones no siempre tratadas a la hora de abordar temas relacionados con la evolución de los Estados Nacionales (las Repúblicas y sus luchas ideológicas). 
Las anteriores matrices epistemológicas entendidas como posibilidades analíticas en sus múltiples significados, las enmarcamos en procesos mayores que engloban la época y sus contextos, es decir, en el ascenso del pensamiento liberal burgués, en la quiebra de los imperios (hispánico y portugués), en la nueva expansión europea, en la consolidación del capitalismo, en el avance de la revolución industrial, los romanticismos discursivos y las ideologías nacionales (Altez, 2015: 11).

Dichos momentos y contextos son desarrollados en un segundo apartado, al que se ha denominado iconografías garibaldinas, concentrándonos en Giuseppe Garibaldi, un revolucionario declarado héroe nacional en Italia (1882) y quien por sus expediciones en América inspiró relatos discursivos románticos e ideologizados en tiempos de plenas revoluciones, de intensas y dilatadas luchas. $\mathrm{Su}$ efecto seductor y envolvente nos facilita mostrar cómo han sido descritos literaria y artísticamente los relatos y sus posibles efectos comunicativos inspirados en su figura.[2]

Para esto, se ha tomado cuenta algunos eventos-acontecimientos en que participó Garibaldi en América del Sur como en Europa. En Brasil la historiografía decimonónica exaltaba con elocuencia el triunfo del proceso de independencia, viendo a la monarquía con afecto, admiración y respeto (Pimienta y Ferraz, 2015:1 57)[3]. De hecho, las versiones del siglo XIX, consideraban que el continuum del régimen monárquico habría sido garantía para su unidad territorial (Vianna, 1975).[4] Entre tanto en Italia, luego de cruentas batallas que lucharon por formar el núcleo de un movimiento nacional para la Unidad de Italia, el parlamento proclamó a Vittorio Emanuele II Rey de Italia, finalizando la fase épica del resurgimiento. Italia debía crear una administración homogénea y encuadrarse en un Estado Nacional (Scalmani, 2016: 303).

Todos estos aspectos serán tratados desde un enfoque trasnacional e interdisciplinar. Metodológicamente se emplea la heurística y hermenéutica para tratar textos históricos; para las obras artísticas nos basaremos en el método preiconográfico-iconográfico-iconológico panofskyano.

\section{Posicionamientos epistémicos}

\subsection{Significación de realidades}

Hay momentos en que los imaginarios entran en crisis perdiendo autoridad y credibilidad colectiva sobre todo cuando la realidad historiográfica en sus explicaciones históricas no logra sostener el discurso que le daba legitimidad (Cabrera, 2005: 143). Construidos colectivamente y codificados por una sociedad para representar una realidad, los imaginarios mantienen una directa relación con la memoria colectiva mediada por valoraciones ideológicas e identitarias. Los imaginarios como significación y creación de realidades dan sentido a mentalidades socialmente compartidas.

Desde este punto de vista, la Historia de las ideas y de los imaginarios se ocupan de reconocer lo simbólico confrontando las realidades que representan. Los imaginarios sociales son fuente para la comprensión de esquemas interpretativos de los grupos sociales (Le Goff, 1995: 13). Al contar 
con una materialidad tangible (documentos y monumentos) e intangible (mitos y cosmovisiones) establecen una ligación efectiva con las obras, las culturas y sus objetos. Un ejemplo, son los monumentos erigidos para rememorar sacrificios, ritos, creencias y acontecimientos. Estos actúan sobre la memoria, invocando pasados localizados y seleccionados para fines específicos (Choay: 2018).

Los imaginarios son capaces de fusionar hechos en cuanto a acontecimientos fácticos con ficciones, por tanto, no están disociados del contexto mentaly de una visión de mundo. Esta condición compleja hace que la realidad construida se dote de imágenes idealizadas respondiendo a una multiplicidad de racionalidades, de ahí, la necesidad de asignarles referenciales socioculturales y epistémicas (Martínez, 2014: 14).

Disciplinariamente las realidades pasan a ser parte de la observación y de la crítica científica. Los agentes epistémicos al contar con un rol activo para intervenir en la realidad deben tener la propiedad de aplicar la objetividad, esto es, "sí y solo sí, se sanciona la distinción entre sujeto observador (o sistema de observación) y realidad (o sistema de referencia)". Entre sujeto observador y realidad, "hay cierta transacción llamada experiencia (o experimentación)" (Galassi, 2014: 107).

En relación con el sistema de observación aplicado a los acontecimientos sociales es el sistema científico quien tiene la tarea de facilitar los conocimientos sobre la realidad, atribuyéndole meta niveles a la observación. De esta manera, las posibilidades de conocimiento en todas las formas y medios pueden emplearse para sustentar una afirmación sobre la realidad (Becker, 2016: 63).

En la práctica, lo real siempre tiene un componente epistémico y metafórico no fácilmente aprehensible. Por ejemplo, en el sigloXIX la verdad fáctica fue sinónimo de acontecimiento histórico. Con el auge del positivismo se pasó a la producción de la realidad tomando como fundamento el origen de la fuente para determinar su credibilidad. Las formulaciones decimonónicas de los grandes acontecimientos del pasado sobre datos positivos prefiguraban lo que se quería representar (Rivero, 2013: 53).

La narración de los acontecimientos pasados sometidos a la ciencia histórica fue colocada bajo la sanción imperiosa de buscar lo real; la trilogía (acontecimiento, personaje y trama) en escritos históricos realzaron narrativas. En el discurso histórico, lo real pasó a ser connotación de lo pensable; se produjo un proceso de significación sobre algo real perdido (el pasado), para instalarlo en lugares específicos (museos, documentales, fotografías, archivos y discursos). Lo real era equivalente a lo conocido, al registro de las huellas dejadas por el pasado (De Certeau, 2006: 51).

Las discusiones teóricas asociadas a lo real conocido y a lo real simbólico complejizaron aún más las abstracciones. El retorno a la metáfora fue tema para los paradigmas disciplinares; de tal forma que la metáfora fue vista como "modelo en función pragmática (Blumenberg, 2018). Las posibilidades de lectura abarcaron los sentidos y los significados de las prácticas, es decir, se produce una intersección entre realidad histórica y 
simbolización social. De hecho, la verdad simbólica del acontecimiento va a sobreponerse a la realidad histórica (Rivero, 2013: 62).

\section{Influencia comunicacional del arte sobre la realidad}

Por principio natural el arte difiere de la realidad. Su producto representa una realidad ficcional e imaginaria. Aun así, puede brindar la posibilidad de convertirla en verdadera. Son ejemplo la novela utópica que imagina una nueva forma de sociedad causando resonancia en el sistema político y en el comportamiento social; o el Bauhaus, un movimiento de las artes plásticas que impulsó la arquitectura, el diseño de muebles y el estilo de vida (Becker, 2016: 110).

Aunque por naturaleza no remite a la realidad conforme a la verdad, el arte tiene su propio sistema y código en los diferentes sistemas sociales y psíquicos. Desde la mirada funcional-estructuralista, el arte es un sistema funcional que opera según una lógica propia en el contexto de los demás sistemas de funciones y en acoplamiento estructural con ellos. Desde esta óptica, la realidad del sistema artístico se solidifica con patrones de interpretación y de comunicación (Luhmann, 1995: Valenzuela, 2005: Becker, 2016).

Como medio de comunicación, lo propio del arte yace en su utilización de la percepción y la figuración (la simulación auto provocada de la percepción) para la producción de una realidad. En este sentido, la obra de arte como comunicación compromete a los observadores (Valenzuela, 2005) de tal forma que el arte es vista como una realidad (probable e improbable) que facilita la observación en comparación con otras realidades, por tanto, el arte construye mundos (Becker, 2016: 110-116).

Podría decirse que crea mundos ficcionales con la exploración de posibilidades perceptibles y figurativas; y mundos reales con base en las expectativas y la cotidianidad observada a través de la obra de arte. ¿cómo encaja todo esto con los relatos y las tramas históricas? Principalmente por la necesidad de acudir al arte para visualizar el relato, para traer a la memoria un episodio de manera instantánea y dejarlo instalado en el imaginario. La obra de arte remite a mundos ficcionales de fantasía que recrean el pasado; constituye el último paso en la construcción del mito histórico, de su visualización depende dejarlas grabadas en el imaginario colectivo (Murado, 2014: 126).

Crear y recrear un pasado de apariencia "real" son condición de comunicación en una obra de arte. Como comunicación, la obra también distingue entre entorno y sistema (Luhmann, 1984). Por tanto, se trataría de la expresión de una realidad de segundo nivel que fluye en medio de redes interpretativas. La obra como correlato comunicativo y sistémico expresa un entendimiento sobre una determinada realidad; comunica al observador lo que contiene; involucra al observador a indagar sobre la realidad que se representa; vincula la noción de realidad con la de significado (Capilla, 2014). Desde esta apreciación, la realidad en la obra solo es tal en tanto es observada, de tal forma que siempre que se describe lo real (una pintura o el pasado), está en función de un observador (Mendiola, 2003: 512). 


\section{Relatos republicanos e inspiración literaria-artística}

En el siglo XIX la inminente búsqueda de un orden republicano se desarrolló en medio de múltiples disensos. Es una época en que la realidad no se imponía como criterio absoluto, y solo podría reproducirse, si y solo si, se tomaba la tarea de reconstruir los contextos de emisión, enunciando referentes (memorias institucionales y autobiografías) para acceder a lo real (Mendiola, 2003: 513)[5].

La realidad se fijaba a la institucionalidad del Estado que bajo el lema de nuevo orden republicano propició producciones históricas, literarias y artísticas trazando como propósito fundamental fijar la historia de la construcción de los Estados Nacionales. Apoyados con repertorios gloriosos y libertarios, visibiliza y fija a las nacientes repúblicas y sus ilustres a la manera clásica (efigies, pintura, escultura, literatura, entre otros), manteniendo como tópicos emancipación y libertad.

Las administraciones nacionales no dudaban en ponderar el desarrollo de las repúblicas principalmente ante las sociedades científicas de Europa realzando sus avances científicos y artísticos resultado de la subvención de la ciencia y la cultura[6]. El orden republicano, el arte y la nación en América pasó a ser política de Estado (Sagredo, 2016: 65). Científicos, historiadores, literatos y artistas ofrecían sus servicios a los gobiernos entregando tomos monumentales de historias nacionales aumentando los acervos nacionales; diversidad de obras artísticas que ambientaron lugares emblemáticos como salas provinciales, ayuntamientos, cabildos, congresos y ministerios, entre otros.

Ideales, convicciones, experiencias y realidades divergentes circularon con posturas reflexivas y de resistencia. El "orden republicano" se desarrollaba en medio de incertidumbres y de divergencias ideológicas. El rol comunicador de las producciones histórico-literarias y artísticas fueron piedra angular para la construcción idealizada de nación y para los cimientos de los Estados Nacionales; para dejar en la memoria viva aquellos acontecimientos asociados a revoluciones de carácter republicano y libertarios en sus múltiples interpretaciones y observaciones. Los héroes comenzaron a ser representados como lo que no eran: liberales románticos, jacobinos anti corporativos, o descolonizadores radicales (Rojas, 2010: 29) [7].

Se trataba de escenarios convulsos y revolucionarios republicanos apropiados histórica, literaria y artísticamente en el marco de eventos-acontecimientos en contextos de revueltas regionales. Entre 1810 y 1848, las modernas identidades nacionales de la región aún no estaban configuradas; la creación de identidades políticas nacionales durante la primera mitad del siglo XIX fue un proceso sumamente complejo. Las naciones latinoamericanas, tal y como se conocen (desde mediados del sigloXIX) eran entidades simbólicas inexistentes en los años previos y posteriores a la independencia, por lo que demandó un esfuerzo para imaginar e inventar las nuevas naciones (Rojas, 2010: 35). 
Los discursos unionistasy separatistas estuvieron a la orden del día. Específicamente en Brasil fueron tiempos de crisis imperial. Con la abdicación de Pedro I y en medio de un periodo regencial de 9 años, se desató un exacerbado sentimiento antilusitano. La desorganización social y política del periodo regencial germinó revueltas y rebeliones en casi todas las provincias de Brasil; entre 1830 y 1850 fueron constantes las luchas antagónicas entre liberales, monarquistas y separatistas. Fueron épocas de revoluciones contra el poder imperial y el centralismo (Bueno, 2012: 199).

En este ambiente las batallas épicas se tornaban en masacres. El imaginario colectivo cambiaba de posición a los combatientes: unas veces los héroes eran llamados villanos y otras los villanos eran considerados héroes (Bueno, 2012: 204). Ilustrativamente, la llamada revolución Farroupilha es el ejemplo de una guerra duradera y violenta que se prolongó por más de diez años, a tal punto, de dar la sensación de estar lidiando no con una, sino con varias guerras distintas. [8] Corresponde a un conflicto motivado por causas ideológicas, económicas y políticas; fue una guerra de guerrillas típicamente platina, luchada a caballo, repleta de actos de heroísmo, tácticas, combates sangrientos y héroes controversiales. Durante muchos años la guerra fue un tema tabú, siendo prohibido escribir sobre ella. Solo en 1870 apareció en Brasil, el primer libro sobre el conflicto, eran Las Memorias de Garibaldi, escrita por Dumas (Bueno, 2012: 207).

Giuseppe Garibaldi fue uno de los revolucionarios con gran resonancia latinoamericana y continental pasando a la historia como un gran héroe libertario[9]. Reconocido como general, guerrillero, condotiero y patriota italiano, es entre los mercenarios rebeldes, uno de los que mayormente ha inspirado relatos y escenas épicas[10]. Literariamente su vida fue inmortalizada por su amigo y admirador Alexandre Dumas, encendiendo la imaginación de miles de lectores y escritores, y del mismo Garibaldi con la producción de una autobiografía[11]. El poeta Rubén Darío lo llamó prodigioso mosquetero de la Libertad y aventurero de la Gloria. No solo centros hospitalarios e institutos de beneficencia tomaron su nombre[12]. Esculturas, monumentos, plazas y calles distribuidos en todo el mundo hacen referencia a Garibaldi[13].

Su participación en ambientes polarizados de disputas entre separatistas y unionistas vio nacer efímeras repúblicas, como la Independiente Riograndense (Brasil) y la Romana (Italia); vivenció gobiernos post-unitarios que eligieron el camino hacia la centralización autoritaria (la Italia de 1861-1864); presenció la caída del imperio sustituido por la Tercera República, la liberación de Roma en 1870 tras la derrota de Napoleón III en la guerra con Prusia; experimentó influencias del socialismo inglés al igual que otros demócratas italianos como Mazzini (promotor de la Unidad Italiana); caminó en medio de fricciones ideológicas y políticas entre Iglesia, Estado e Imperios; abogó por idearios de sociedades y logias masónicas y por la revolución social de los trabajadores. Su vida transcurrió frente a un sistema de autoridad inestable y cambiante[14].

Siempre en combate, ha inspirado a artistas de todos los tiempos y géneros. Estampas, retratos, 
obras teatrales, pinturas, esculturas, monumentos, objetos conmemorativos, novelas y miniseries[15]. En la actualidad su memoria y exaltación se mantiene viva, con alusiones festivas performáticas $\left[{ }^{[6]}\right.$.

\section{Iconografías garibaldinas}

\subsection{Representaciones pictóricas e imaginarios}

El especialista semiólogo Omar Calabrese al catalogar las iconografías "garibaldinas" propuso una "iconografía alta"- que examinaremos más en detalle-; una iconografía de "transformación"; una "iconografía de masa" y una "popular". Ya desde las primeras páginas de su libro, titulado llamativamente "Garibaldi tra Ivanhoe e Sandokan" publicado en 1982 emerge el retrato de un héroe propio de un imaginario colectivo, cultural, histórico y cotidiano.

Las primeras dos iconografías están muy relacionadas entre ellas, ya que la "alta" se reconduce a aquellas representaciones pictóricas- por ejemplo, en exposiciones de arte- que presentan las características formales y el lenguaje plástico distintivo de la pintura decimonónica; a su vez, la "de transformación" deriva de una trasposición dibujística de dichas obras en otros soportes diferentes al lienzo (figs.1, 2)[17].

Fig. 1 Fratelli Terzaghi, Giuseppe Garibaldi en Caprera, litografía, 1860 ca.

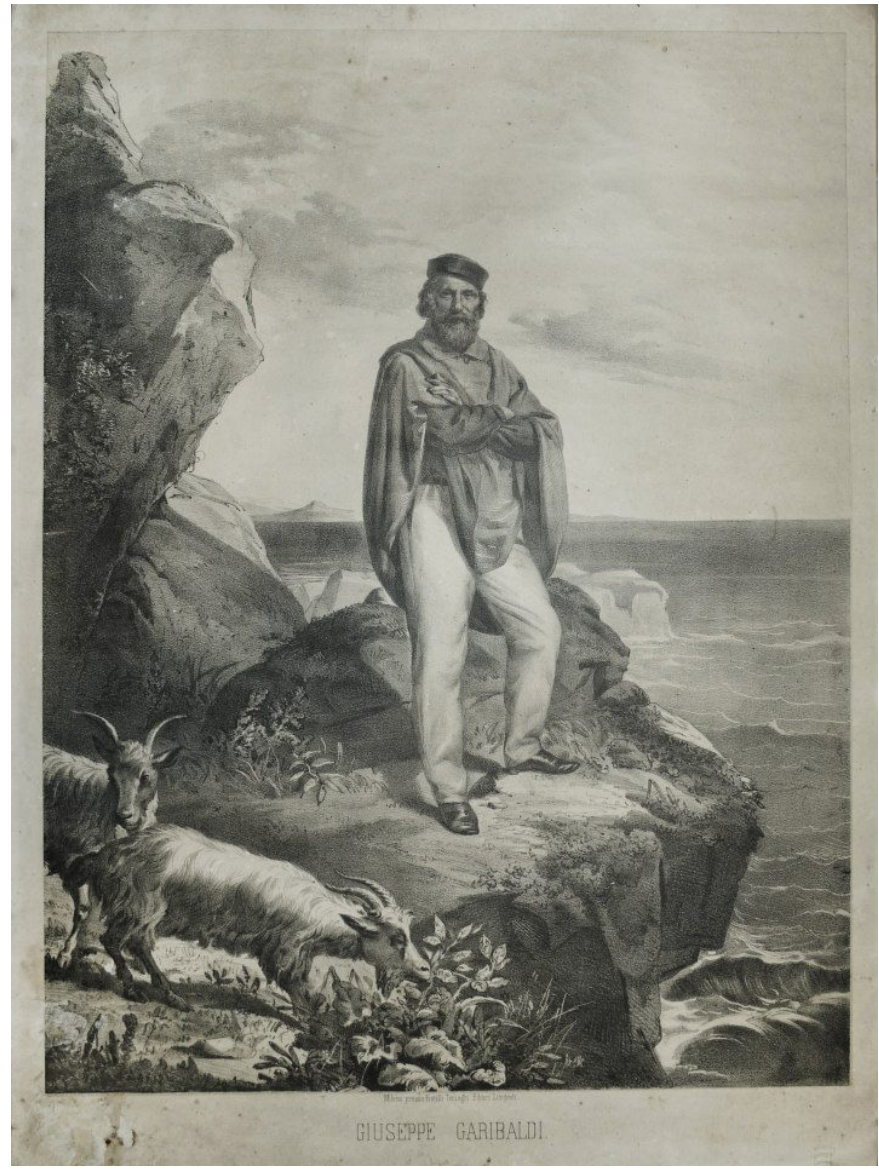

Fuente: Centro Studi Iconográfici Giuseppe Garibaldi, Colección Alessandro Ceccotto, Adria, (Rovigo), Italia.

Fig. 2 Sello conmemorativo de los 50 años de la muerte de Giuseppe Garibaldi.

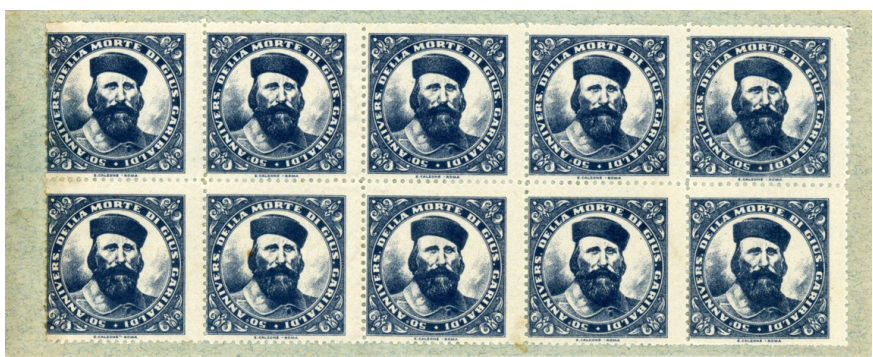


Fuente: Centro Studi Iconográfici Giuseppe Garibaldi, Colección Alessandro Ceccotto, Adria, (Rovigo), Italia.

Del mismo modo la relación entre la iconografía de masa y popular nos resulta de fácil comprensión porque la "de masa" circuló alimentada por los cimelios (objetos de uso personal y doméstico) y los anuncios de productos comercializables (figs 3 , $4,5)$, en tanto que, la "popular", es sostenida por sujetos icónicos como Garibaldi protagonista de viñetas narrativas o de su propia "hagiografía" (Arangio 2015) (fig.6).

Fig. 3 Colgante con perfil de Garibaldi, en hueso y cornisa de plata, 1892.

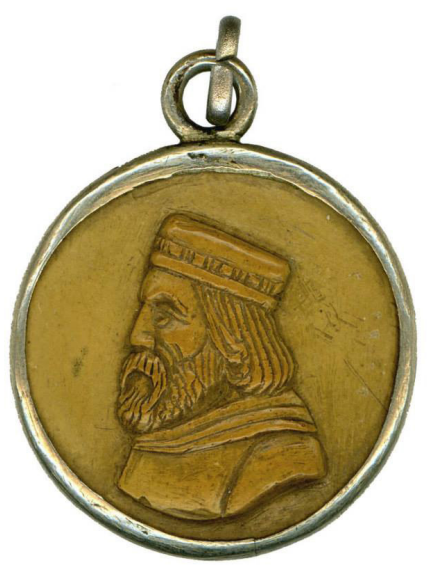

Fuente: Centro Studi Iconográfici Giuseppe Garibaldi, Colección Alessandro Ceccotto, Adria, (Rovigo), Italia.
Fig. 4 Colgante en forma de busto de Garibaldi, $\mathrm{r} / \mathrm{v}, 1882$.
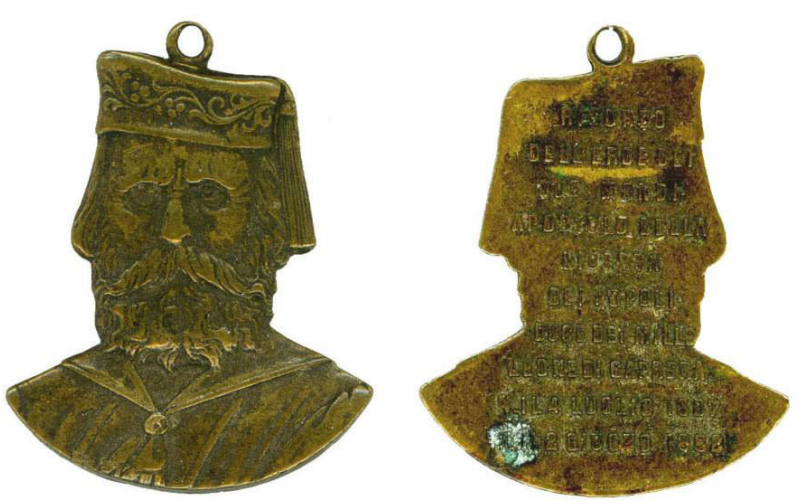

Fuente: Centro Studi Iconográfici Giuseppe Garibaldi, Colección Alessandro Ceccotto, Adria, (Rovigo), Italia

Fig.5 Reclame para cerveza brasilera, finales deXIX

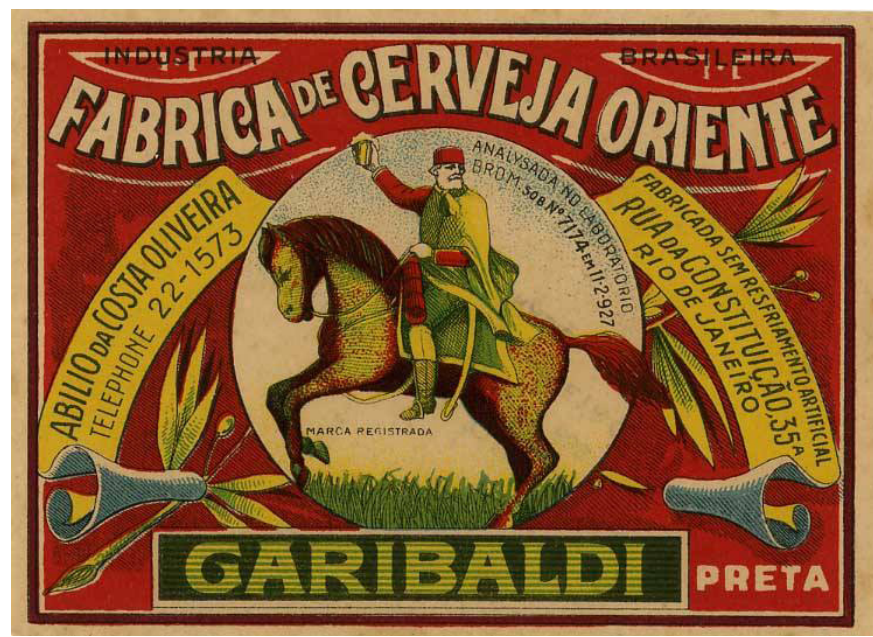

Fuente: Centro Studi Iconográfici Giuseppe Garibaldi, Colección Alessandro Ceccotto, Adria, (Rovigo), Italia. 
Fig. 6 Calendario año 1863, Litografía.

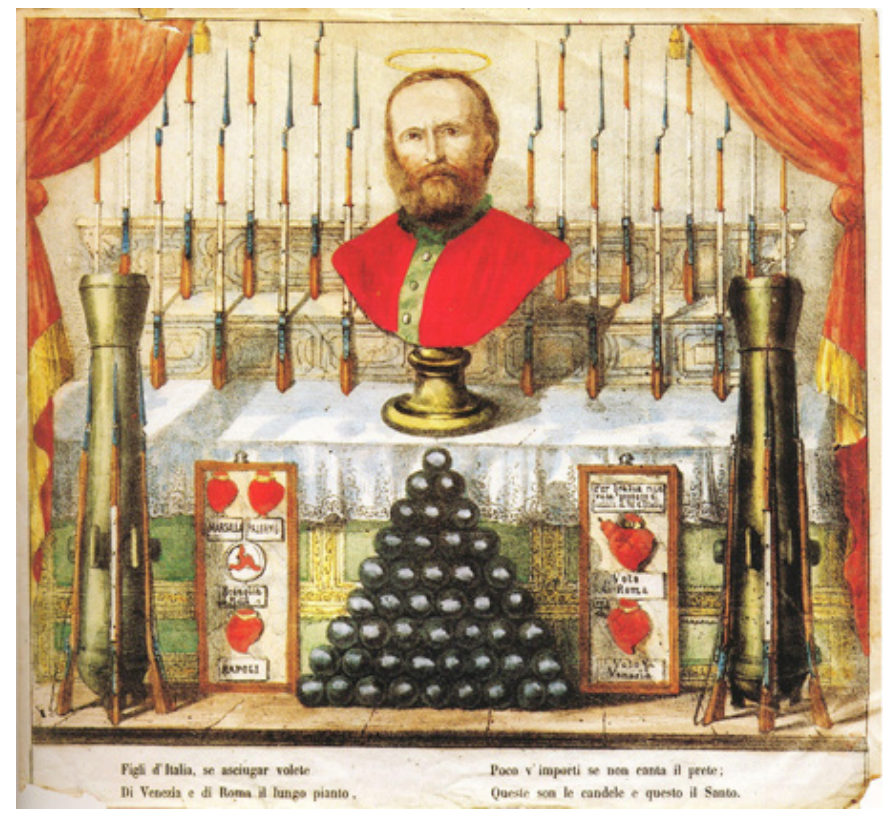

Fuente: Musei Civici, Raccolta Bertarelli- Milán.

En la memoria colectiva Garibaldi era recordado a decir de Calabrese como un ser extraordinariamente polimórfico, admitiendo su gran significación en la vida cotidiana:

[...] lo recuerdo mirarme desde el libro de historia de las escuelas primarias: un héroe en plena regla, moral, fuerte, invencible, descrito en un lenguaje muy reducido, pero no menos retórico. Debo admitir: un Garibaldi un poco desagradable, tan envuelto en ideales incorruptibles y ansias de una muerte hermosa. Junto a esto, sin embargo, hay un héroe aventurero diferente y colorido. Es el Garibaldi de las pegatinas que combinaban con un conocido chocolate, que constituía el núcleo de mi merienda escolar, mientras que esas, las pegatinas, constituían el núcleo de mi primera actividad como coleccionista (luego vendrían los jugadores, luego los sellos, y luego todo lo que se refiere a la formación de una sólida cultura humanística) (Calabrese, 1982: 5, Tda).

\section{Espíritus revolucionarios y patrióticos en obras artísticas}

Históricamente se reconoce la animadversión de la Monarquía hacia Garibaldi. Es de recordarse que las Exposiciones Nacionales se celebraban al amparo y bajo el ojo atento del Gobierno.

Fig. 7 Filippo Palizzi, Garibaldi a caballo.

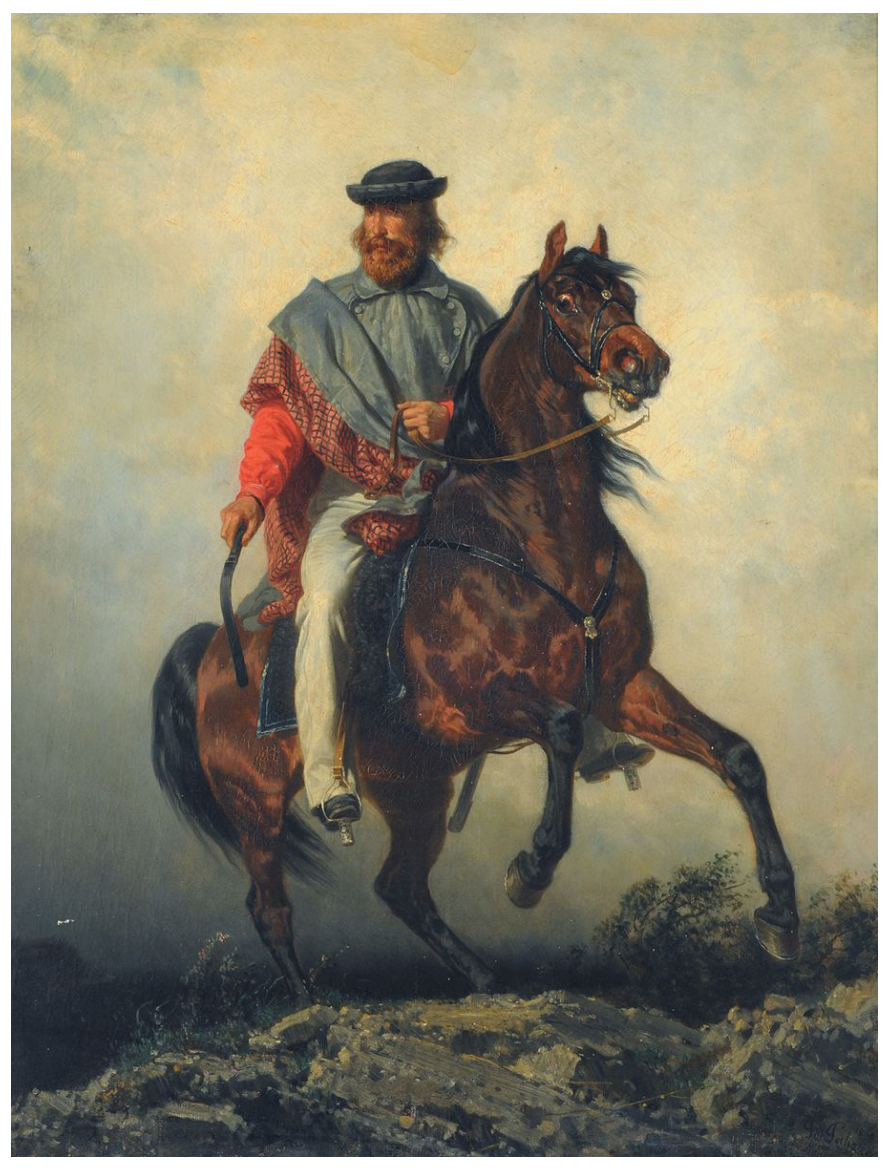


Fuente: Museo Nacional de Bellas Artes de Buenos Aires, 1860

Esta obra procede de los pinceles de Filippo Palizzi (fig.7), el artista que junto con Domenico Morelli fue protagonista y renovador de la escena pictórica del sur de Italia en la segunda mitad del siglo XIX. Esta versión se remonta al año 1860 y se conserva en el Museo Nacional de Bellas Artes de Buenos Aires tras ser donada a la institución en el año 1911. En los años de realización de la obra, Garibaldi ya gozaba de notoriedad, contaba con el consenso del público tanto europeo como americano y su fama iba creciendo hasta rozar la leyenda en vida.

La tipología elegida por el pintor es la del retrato ecuestre cargado de simbolismo patriótico con potencia discursiva y narración formativa en perfecta síntesis. Ya en los años inmediatamente anteriores a la realización de esta tela de grandes dimensiones, Palizzi se había cimentado en el mismo tema de Garibaldi a caballo, en una composición de menor tamaño, octagonal y para enmarcar, cuya reproducción acompañará el artículo de Ciro Caversazzi publicado en el "Numero Garibaldino" de Emporium. Rivista mensile illustrata d'arte e cultura, para conmemorar los 50 años de la muerte de Giuseppe, titulado "L'Eroe dei Due Mondi" (1932: 258) (fig.8).
Fig.8 Filippo Palizzi. Garibaldi a cavallo

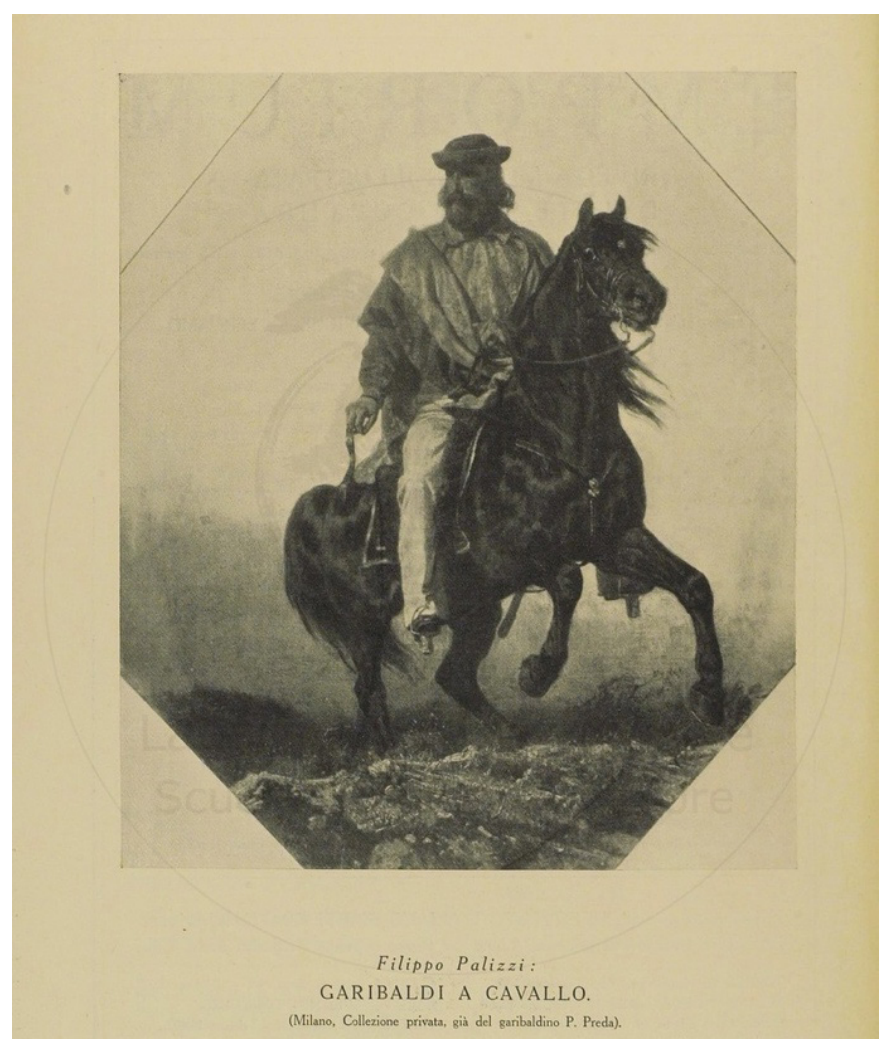

Fuente: Milán, Colección privada. Litografía publicada en 1932

En el oleo Garibaldi está representado en una actitud fiera pero no beligerante, erguido en el caballo que, en el segundo plano iconográfico, comparte protagonismo con el centro cromático de la misma, eso es, el atuendo del jinete.

Garibaldi había sido comandante de una fuerza naval irregular en Sudamérica, volvió a Italia como jefe de la guerrilla revolucionaria y héroe de la independencia de Uruguay para unirse a la guerra de independencia italiana junto a un cuerpo de voluntarios (Scalmani: 284). Como 
prueba documental de esta presencia en ambos continentes, Palizzi funde elementos de la moda europea y de la americana que se complementan para dar vida al estilo distintivo del nizardo a su regreso de Sur América: los pantalones vaqueros que mantiene ceñidos a la cintura, la inolvidable camisa roja y el poncho azul doublé face- admirablemente iluminado gracias al claroscuro acentuado-doblado en la espalda para dejar entrever la capa inferior.

En particular la camisa fue la prenda símbolo de los que voluntariamente se unieron a la causa garibaldina y de los que compartían su ideología política tanto en América como en Europa:

Portarla era un desafío silencioso y una ostentación pública de la fe patriótica. Esa provocación llevaba de forma casi directa al contacto violento, o al menos mostraba disponibilidad a aceptar un cuerpo a cuerpo. Facilitaba una identificación lírica [...] La prenda era como un talismán que contagiaba el espíritu revolucionario, que representaba "un pasado que se apagará" con la desaparición de quienes la habían llevado. Era el símbolo de la superación de la tradición del patriotismo conspirativo, que ahora salía a la luz pública. La nación de las camisas rojas es la imagen de Italia - real o deseada - de los discursos y escritos de Garibaldi, pero también es la interpretación del Risorgimento italiano que se consolida en el extranjero. (Cañas, 2014: 14)

Dicha constante cromática se mantendrá hasta perfilarse como rasgo identitario (y por ende por elemento iconográfico e iconológico) de la imagen de Garibaldi en ambos continentes.

En la obra con la que seguimos nuestro recorrido visual (fig.9), continúa siendo el centro de la representación, en este caso se trata del oleo de otro exponente de la pintura decimonónica de aquellos años, Gerolamo Induno (1825-1890), a menudo definido "il pittore del Risorgimento" [18].

Fig.9 Gerolamo Induno, Giuseppe Garibaldi e il Generale Giacomo Medici incontrano il Re Vittorio Emanuele II.

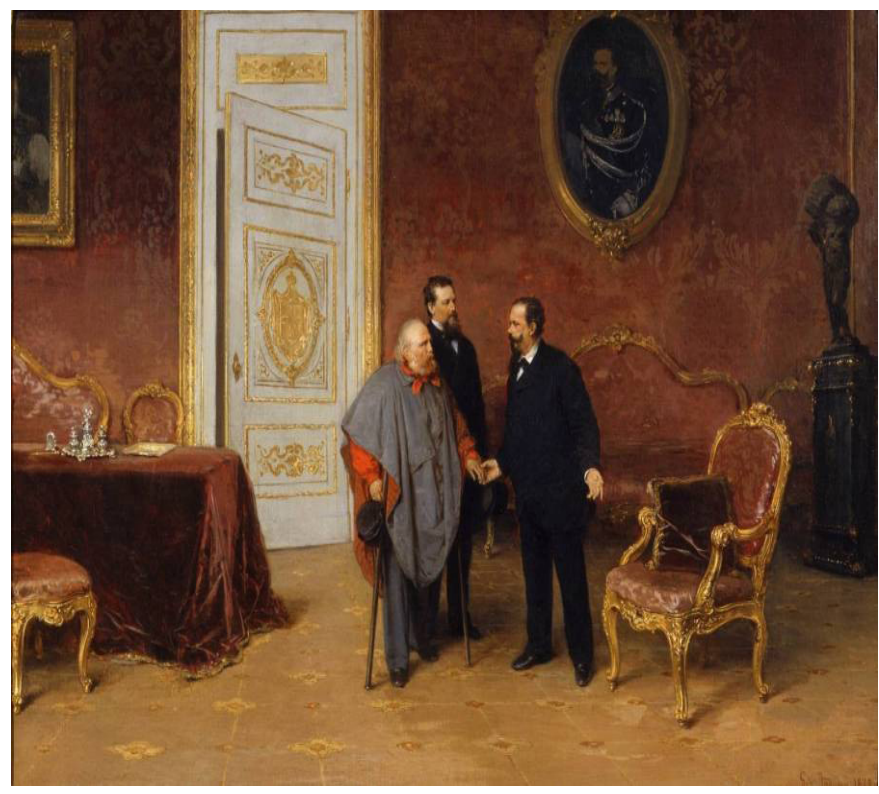

Fuente: Roma, Palzzo del Quirinale, 1870 ca.

Sus pinceles encarnan el espíritu patriótico que en Italia permeaba capilarmente cada sector de la sociedad inclusive el de las Bellas Artes que no se sustrajo al fascino carismático de Garibaldi, de su discurso y, por ende, de su imagen (AAVV, 2014).

La obra de Induno se conservó en el Museo del Risorgimento en Milán, lejos de los ojos del público 
hasta el año 2015. A petición del Presidente de la República Italiana, Sergio Mattarella, volvió a Roma para ser expuesto en la misma sala del palacio que fue teatro de la escena representada, la sala de las audencias particulares en la primera planta del Palazzo del Quirinale (Il Giornale, 2015).

En el óleo se puede admirar el encuentro celebrado el día 30 de enero de 1875 entre Garibaldi, acompañado por Giacomo Medici del Vascello-el teniente que estuvo con él desde los sucesos en Uruguay y que se había distinguido en los tiempos de la República Romana (1849)- y el rey Vittorio Emanuele II.

Toda la escena está envuelta en un sin fin de matices de rojo, desde las paredes, hasta el terciopelo que cubre la mesa a la izquierda y los tapizados de los numerosos sillones a lo largo de la sala. Los insertos de oro completan la elegancia del espacio en el que el rojo encendido de la camisa de Garibaldi es el elemento que llama sobre si la atención de quien mira el cuadro y que, junto con el poncho azul, ayuda en el reconocimiento inmediato del personaje retratado.

Si bien existen posteriores reproducciones a gran escala estamos delante de una diminuta obra que hasta en sus medidas quiere recrear la cercanía del vis a vis en acto. Estamos lejos de las imágenes de Garibaldi combatiendo e incitando las masas en su hazaña desde Marsala a Roma. Sin embargo, en el esbozado gesto del brazo, la heroicidad de Giuseppe, íntima y contenida es aún más celebrada. Veamos en detalle.
En el momento del encuentro, Vittorio Emanuele II es Rey de Italia en una Roma que desde unos años es la capital y que Garibaldi no visitaba desde hacía más de 30 años, es decir, desde los aclamados hechos dela República Romana. Dadas sus condiciones físicas, Caprera se ha convertido en el lugar donde transcurría la mayoría de su tiempo, así que la noticia de la visita al Rey es, una vez más, sentida como un acontecimiento especial por quienes siguen sus noticias.

Medici viste un traje negro dada la presencia real, Garibaldi no ha renunciado a su atuendo distintivo, con el pañuelo rojo atado en el cuello y gorro en mano en señal de respeto. La barba, el pelo, las muletas en ambos brazos, todo narra su vejez y delata sabiduría y madurez.

El rey está ataviado de manera muy similar a Medici, "in abiti borghesi, sembra più un possidente di provincia che il primo Re d'Italia" ("lleva indumentos burgueses, más que el primer Rey de Italia, parece un terrateniente de provincia", tda, Il Giornale, 2015). Está muy cerca de Garibaldi y le toma la mano casi timidamente. Como bien relata Franco Ragazzi en el catálogo de la exposición sobre retratos de grupo edito por el citado Calabrese, celebrada en Roma en el Palazzo Venezia en el año 2003:

La epopeya heroica del Risorgimento había terminado, el espíritu del encuentro de Teano ya no existía, Garibaldi había agotado la confianza depositada anteriormente en la monarquía. El general, agobiado por los años, magullado por los reumatismos cada vez más graves que le obligaban a sostenerse 
con muletas, concede al rey, que había desaprobado las acciones por la liberación de Roma e incluso ordenó que les dispararan, que le estrechara la mano (Ragazzi, en Calabrese 2003: 29, Tda).

Una vez más, Garibaldi resulta el personaje positivo y ensalzado como hombre virtuoso en su capacidad de relacionarse con el Rey (fig. 10). El encuentro marca el pasaje de poderes en los territorios italianos desde un gobierno dictatorial al rey, Vittorio Emanuele II, oficializado gracias a las palabras que Garibaldi pronunció a los ejércitos presentes: “ $¡ E c c o$ il Re d'Italia! ¡Salute al Re d'Italia!"

La potencia comunicativa del momento inmortalizado por pintores y reproducido hasta la saciedad en infinitos soportes hasta bien entrado el siglo $\mathrm{XX}$ (lienzos (fig.10), estampas, platos, monedas, postales (fig. 11), sellos, abanicos, tazas, hollas, bufandas, garrafas, hasta barriles pastorales) aseguró al evento resonancia tanto europea como americana, hasta ser definido "un evento mediático ante litteram” (Il Giornale, 2015).
Fig.10 Carlo Ademollo, Garibaldi y Vittorio Emanuele II en Teano.

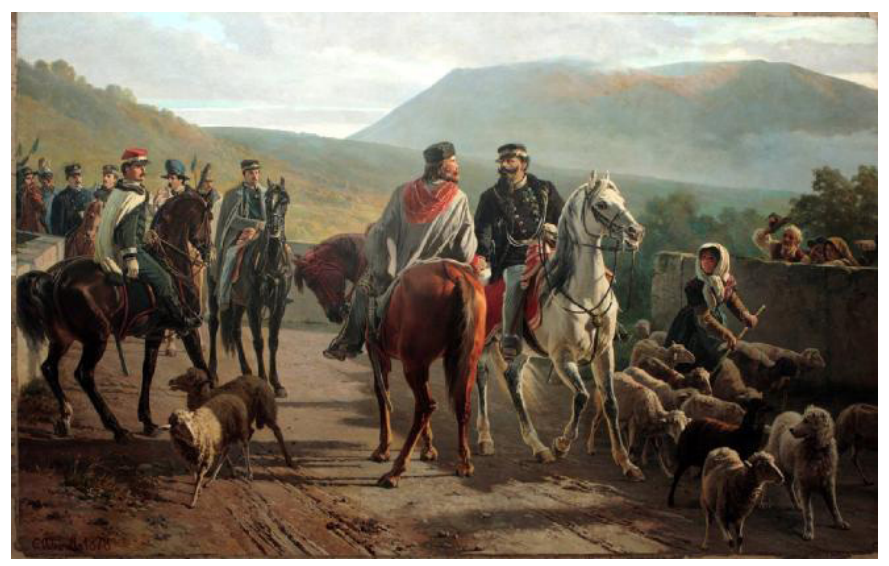

Fuente: Roma, Palazzo Montecitorio. 1878.

Fig.11 Tarjeta postal. Vittorio Emanuele II e Garibaldi (El alto a la derecha, el episodio del "Encuentro de Teano").

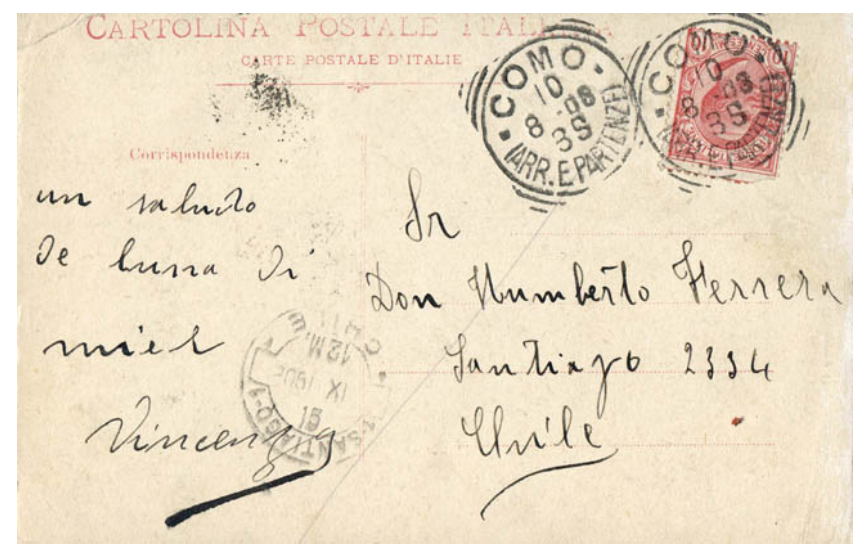




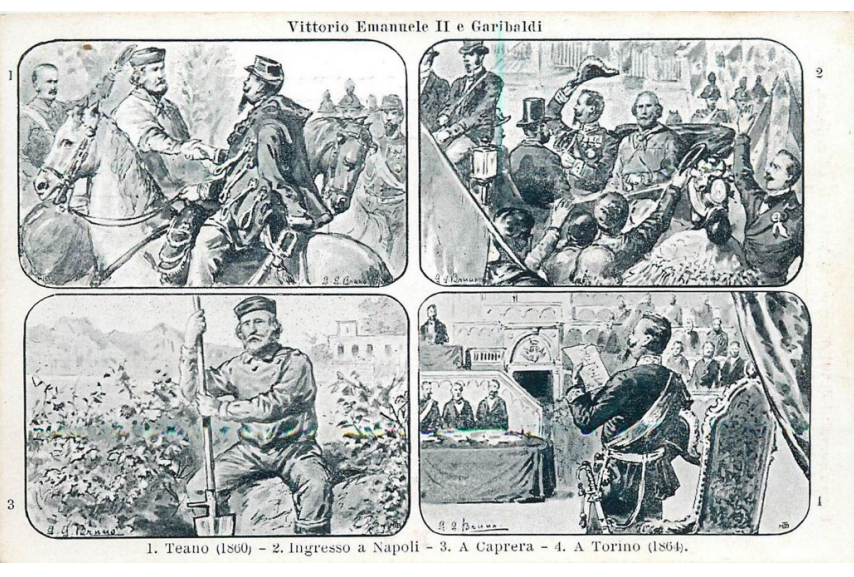

Fuente: Centro Studi Iconográfici Giuseppe Garibaldi, Colección Alessandro Ceccotto, Adria, (Rovigo), Italia, 1900.

Si bien en estas representaciones prima una atmósfera triunfadora y de complicidad entre los dos personajes- ambos cerca al clímax de sus carreras- las crónicas de los que presenciaron los hechos, como en los escritos de Jessie White Mario (1886: 416), reportan el descontento y división entre los presentes, especialmente visible en Garibaldi[19].

Finalmente cerramos nuestro recorrido visual con un objeto peculiar para entender el calado y la perduración que la imagen heroica de Garibaldi tuvo también en América. Es una pequeña postal que se guarda en el Museo Vicuña Mackenna de Santiago de Chile (fig.12), en la que el remitente, un recién casado Vincenzo de luna de miel en el año 1910, envía a la capital andina una tarjeta postal con el monumento ecuestre del nizardo en la Plaza Benedetto Cairoli de la cercana Milán.
Fig. 12 Tarjeta postal, Milano- Monumento a Giuseppe Garibaldi (r/v).

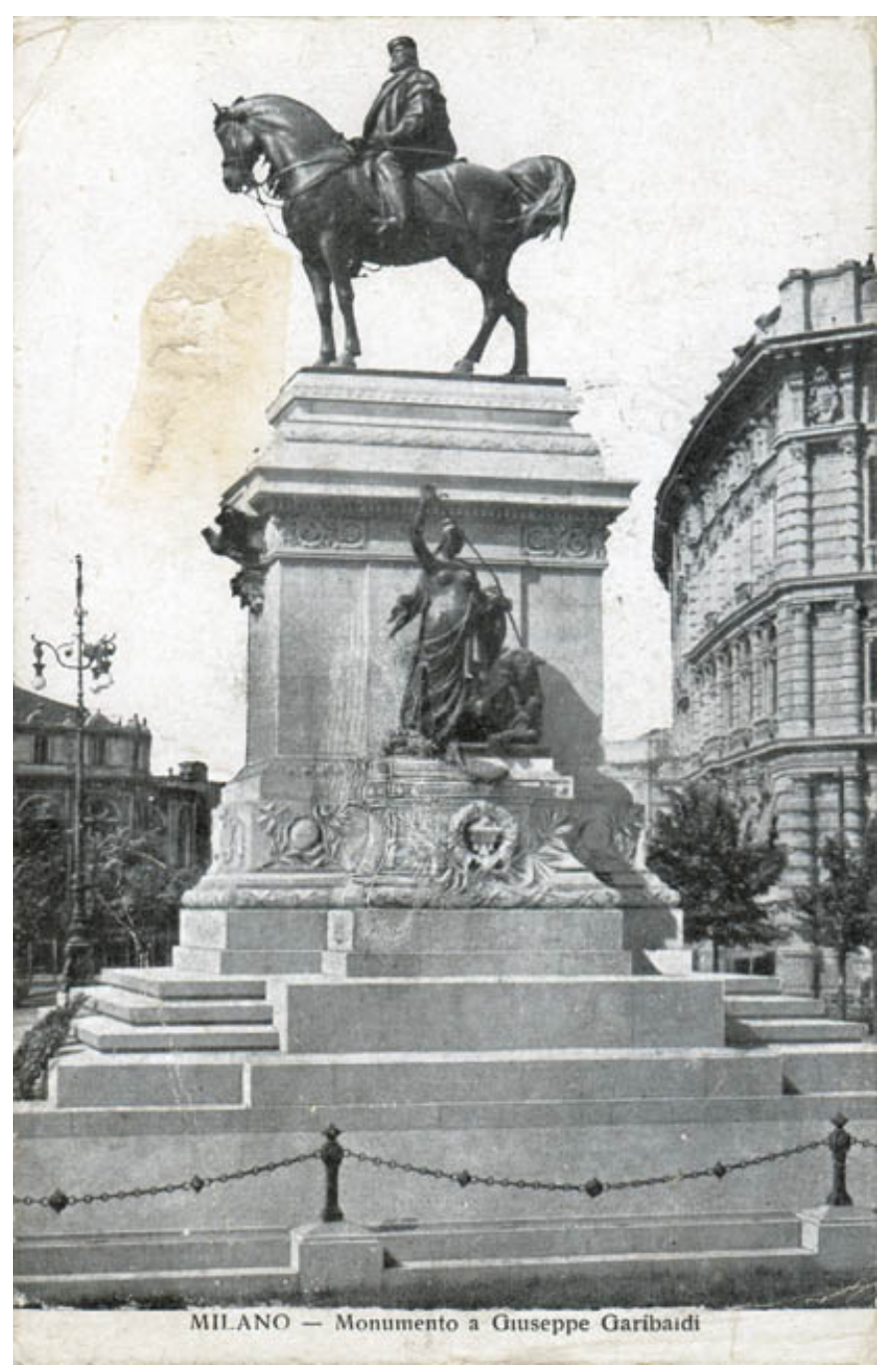

Fuente: Santiago de Chile, Museo Benjamín Vicuña Mackenna, 1910

\section{Conclusiones}

En el caso emblemático de Garibaldi, vimos cómo la resonancia de un revolucionario encuentra su explicación historiográfica en el campo de la batalla política y de la resistencia (Soler y Valenzuela, 2020). En ambientes polarizados de disputas entre 
separatistas y unionistas (federalistas y centralistas) y de indefiniciones a la hora de actuar en uno y otro bando, lo episódico abanderado por un líder, se muestra como un correlato comunicativo que expresa un entendimiento sobre lo que está sucediendo. El líder comunica determinada realidad al observador y muestra el devenir. Es decir, alimenta al imaginario colectivo.

Empero esa resonancia no sería tal, si estuviera totalmente alejada de la realidad experiencial y vivencial. La conexión estaba mediatizada por multiplicidad de tensiones y dilemas que atravesaban las Repúblicas del XIX, cuyos tópicos eran revolución y república, exilios-y retornos-, utopías y desencantos ideológicos (Rojas, 2010: 10).

Como puede constatarse las realidades, las tramas e invenciones literarias y artísticas inmersas en una historia nacional, estaban construidas a partir de idearios que gobernaban la producción de los relatos, independientemente si estos eran de dominación o de resistencia. Desde luego, sus efectos socializadores y usos políticos fueron y siguen siendo utilizados como hechos políticos y sociales plenamente instalados en las memorias colectivas. En todo esto actúan con un rol activo los saberes disciplinares que en el siglo XIX mantuvieron una estrecha relación con la ficcionalización de relatos históricos y la creciente cultura literaria y artística.

\section{Referencias citadas}

Altez, R. y Chust, M. (2015): Las revoluciones en el largo siglo XIX latinoamericano, Madrid, Asociación de
Historiadores Latinoamericanistas Europeos, Ahila.

Aguilar, J. y Rojas, R. (2002): El republicanismo en Hispanoamérica. Ensayos de Historia Intelectual y política, México, Fondo de Cultura Económica.

Amato, G. y Peluffo P. (2011): Alfabeto italiano. Fattie persone di una storia al presente, Milán, Edizioni della Universidad Boccioni.

AAVV (2014): Giuseppe Garibaldi e il suo mito nella pittura. Opere dalla Collezione Tronca, Torín, Il Cigno GG Edizioni.

Arangio, S. (2015): “Alle origini dell'iconografia garibaldina: note su alcune rappresentazioni dell'eroe tra il 1848 e la Seconda Guerra d'Indipendenza”, en Annali online Università di Ferrara, Lettere (AOFL), 2, pp. 2-30.

Arellano, J. (1999): Giuseppe Garibaldi, héroe de dos mundos en Nicaragua, Nicaragua, Publicidad Arellano Vásquez.

Becker, F y Reinhardt, E. (2016): Teoría de Sistemas. Una introducción para las ciencias históricas y las humanidades, Colección el giro historiográfico, México, Universidad Iberoamericana.

Bindis, R. (2006): Pintura chilena 200 años. Despertar, maestros y vanguardias, Santiago, Origo Ediciones.

Blumenberg, H. (2018): Paradigmas para una metaforología, Madrid, Editorial Trotta. 
Bueno, E. (2012): Brasil uma História. Cinco séculos de um país em construção. Rio de Janeiro: Editora Casa da Palavra.

Cabrera, M. (2005): “Hayden White y la teoría del conocimiento histórico. Una aproximación crítica”, Pasado y Memoria contemporánea, 4, pp. 117-146.

Calabrese, O. (1982): Garibaldi tra Ivanhoe e Sandokan, Milán, Electa.

Calabrese, O. (2003): Persone. Ritratti di gruppo da Van Dyck a De Chirico, Milán, Silvana Editoriale.

Cañas, A. (2018): Giuseppe Garibaldi, “l'eroe avventuriero della nazione", comunicación presentada en el VI Encuentro Internacional de Jóvenes Investigadores en Historia Contemporánea, Zaragoza 6-8 septiembre 2017.

Caversazzi, C. (1932): “L'Eroe dei Due Mondi” en Emporium. Rivista mensile illustrata d'arte e cultura, 5 (449), pp. 258-272.

Cegarra, J. (2012): “Fundamentos Teórico Epistemológicos de los Imaginarios Sociales", en Cinta Moebio, No. 43, Santiago de Chile, pp. 1-13.

Choay, F. (2018): The invention of the historic monument, Cambridge University Press.

Cirocco, A. (2007): "Garibaldi: Citizen of the world", Princeton, Princeton University Press.

Cruz, I. (1984): Arte: Lo mejor en la Historia de la pintura y escultura en Chile, Santiago, Editorial Antártica.
De Certeau, M. (2006): La escritura de la Historia. México: Universidad Iberoamericana de México.

De la Maza, J. (2010): "Por un Arte Nacional. Pintura y esfera pública en el siglo XIX chileno” en Sagredo, F (Editor), Ciencia-Mundo. Orden republicano, arteynación en América, Santiago de Chile, Universitaria- Centro de Investigaciones Diego Barros Arana. pp. 281-320.

Dumas, A. (1859): Garibaldi e Montevideo. Milano, F. Manini. https://curiosity.lib.harvard.edu/ latin-american-pamphlet-digital-collection/cata$\log / 43-990052684070203941$.

Fere, M.O.(1860): Garibaldi: sus aventuras, expediciones y empresas en América, Piamonte, Sicilia y Nápoles en 1834, 1848, 1858,1860: obra que comprende los más curiosos episodios y los hechos más importantes en el orden militar y político del actual dictador de Sicilia, Imprenta y Librería de Gaspar y Roig, Editores.

Ferrero, A. (2011): La presenza di Garibaldi in Peru. Lima, Universidad de Lima.

Galassi, J. (2014): "La perspectiva del realismo en las ciencias sociales", en Osorio, F. Epistemología y Ciencia Sociales: ensayos latinoamericanos, Santiago de Chile, LOM, Ediciones, pp. 103-124.

Garibaldi, G. (1861): "Garibaldi: una autobiografía", Tr. Robson, William. Londres, Routledge, Warne \& Routledge.

Garibaldi, G. (2004): “Mi vida”, Tr. Parkin, Stephen, Prensa Hesperus. 
Granados, A; Marichal, C. (2004): Construcción de las identidades latinoamericanas. Ensayos de Historia Intelectual, siglos XIX y XX, México, El Colegio de México.

Il Giornale di Milano (2015): Il quadro dimenticato dallo stanzino al Quirinale, 27/06/2015.

Isnenghi, M. (2010): Garibaldifu ferito. Il mito, le favole, Roma, Donzelli Editore.

LeGoff, J. (1995): Pensar la historia, Barcelona, Altaya.

Luhman, N. (1995): El arte de la sociedad, México, Herder-Universidad Iberoamericana.

Luhmann, N. (1984): Soziale Systeme: Grundrib einer allgemeinen Theorie, Frankfurt am Main, Suhrkamp.

McLean, D. (1998): “Garibaldi in Uruguay: A Reputation Reconsidered", The English Historical Review, 13 (451), pp.351-366.

Mendiola, A. (2000): "El giro historiográfico: la observación de observaciones del pasado", Historia y Grafía, 15, pp. 181-208.

Mendiola, A. (s/f): "El giro historiográfico: La observación de observaciones del pasado. Universidad Nacional Autónoma de México, pp. 509-537. Disponible en web:

https://es.scribd.com/document/388302465/Alfonso-Mendiola-El-Giro-Historiografico-La-Observacion-de-Observaciones-Del-Pasado. [Consulta: 01 de febrero de 2021]
Murado, M-A. (2014): La invención del Pasado. Verdad y ficción en la historia de España, Barcelona, Barberá del Valles.

Lima, M. (1989): O movimento da independencia (1821-1822), Sao Paulo, Itatiaia.

Osorio, F. (2014): Epistemología y Ciencia Sociales: ensayos latinoamericanos, Santiago de Chile, LOM, Ediciones.

Palti, E. (2007): El tiempo de la política. El siglo XIX reconsiderado, Buenos Aires, Siglo XXI.

Pereda, S. (1895): Garibaldi, boceto histórico, Montevideo.

Pereda, S. (1914): Garibaldi en el Uruguay, Montevideo, Ediciones el Siglo Ilustrado, Tomo I.

Pereda, S. (1915): Garibaldi en el Uruguay, Montevideo, Ediciones el Siglo Ilustrado, Tomo II.

Pereda, S. (1916): Garibaldi en el Uruguay, Montevideo, Ediciones el Siglo Ilustrado, Tomo III.

Pimienta, J. y Ferraz, M. (2015): “Uma revoluçao interdita: Esboço de uma genealogía da ideia de "nao-indepéndencia” do Brasil, en Altez, R. y Chust, M., Las revoluciones en el largo siglo XIX latinoamericano, Madrid, Asociación de Historiadores Latinoamericanistas Europeos, Ahila, pp. 153-171.

Rama, C. (1968): Garibaldi yel Uruguay, Montevideo, Ediciones Nuestro Tiempo.

Ricoeur, P. (2001): Ideología y utopía, Barcelona, Gedisa. 
Riall, L (2007): Garibaldi: Invention of a hero, New Haven, Yale University Press.

Rivero, F. (2013): "El devenir del acontecimiento en la operación historiográfica", en Historia y Grafía, 41, pp. 43-77.

Rojas, R. (2010): Las Repúblicas de Aire. Utopía y desencanto en la revolución de Hispanoamérica, Buenos Aires, Aguilar Altea. Taurus, Alfaguara.

Sagredo, F (Editor). (2010): Ciencia-Mundo. Orden republicano, arte y nación en América, Santiago de Chile, Universitaria- Centro de Investigaciones Diego Barros Arana.

Scalmani, D. (2016): Historia de Italia, Madrid, Sílex.

Sepúlveda I. (2005): El sueño de la Madre Patria. Hispanoamericanismo y nacionalismo, Madrid, Fundación Carolina, Centro de Estudios Hispánicos e Iberoamericanos.

Soler, L; Valenzuela, C. (2020): “Representación y (re) significación de un héroe moderno. Caupolicán en las retóricas clásicas y nacionalistas", Boletín Americanista, LXX, 2 (81), pp. 177-199.

Valenzuela, F. (2005): "El arte de la sociedad que observó Niklas Luhmann”, Persona y Sociedad, XIX (3), pp. 287-289.

Vianna, H. (1975): História do Brasil, Sao Paulo, Melhoramentos, Edusp.

Viotti, A. (1988): Garibaldi, Barcelona, Editorial Salvat.
White, H. (1992): Metahistoria. Laimaginación histórica en la Europa del Siglo XIX, México, Fondo de Cultura Económica.

White, H. (2003): El texto histórico como artefacto literario, Barcelona, Ediciones Paidós.

White, J. (1886): Della vita di Giuseppe Garibaldi, Milán, Edoardo Sonzogno Editore.

\section{Notas}

[1] En los convulsos Estados Nacionales cargados de inestabilidades sociales, políticas, e ideológicas las invenciones literarias y artísticas alimentaron el imaginario colectivo llevando de la mano a la utopía y la esperanza.

[2] En este caso se ha considerado artístico los siguientes medios de expresión: pinturas, estampas, grabados, escultura y medios audiovisuales.

[3] La historiografía clásica brasilera mantuvo el argumento de la diferenciación del caso de la América española con la portuguesa, en el continuismo y mantención del régimen político. Según esta perspectiva, la no ruptura entre Brasil y Portugal hizo que las transformaciones se dieran de forma natural en el contexto de entonces (Oliveira, 1922)

[4] Omitimos los análisis asociados a independencia y no independencia de Brasil, a los impactos de su separación de Portugal. Al respecto puede verse (Pimienta y Ferraz, 2015).

[5] Apropiamos aquí la idea de Mendiola para problematizar al observador en las explicaciones de la 
realidad; cuando se reintroduce al observador en la explicación. Véase Mendiola (2000; 2003).

[6] A las monumentales obras de Historia Política, se le unieron las producciones artísticas surgido del seno de las Academias de Bellas Artes (Murado, 2014: 122).

[7] Las representaciones utópicas de Hispanoamérica fueron producidas antes de la nación y el nacionalismo. Los primeros republicanos en América, no la entendían como una comunidad homogénea política o culturalmente. Por tanto, poco tienen que ver con la idea republicana antiimperialista de los nacionalismos y socialismo del siglo XX o con los proyectos panamericanistas promovidos Washington, las oligarquías o las derechas latinoamericanas de finales del siglo XIX. Al respecto véase Rojas, 2010).

[8] Historiográficamente existen versiones divergentes sobre la guerra de la Farrapos.

[9] Garibaldi fue declarado héroe nacional de Italia en 1882. El primer monumento en el mundo dedicado en su homenaje es la obra de Stefano Galletti, en la República de San Marino, erigido en 1882.

[10] Entre las obras clásicas dedicadas a Garibaldi están: Fere, M.O. (1860): Garibaldi: sus aventuras, expediciones y empresas en América, Piamonte, Sicilia y Nápoles en 1834, 1848, 1858,1860: obra que comprende los más curiosos episodios y los hechos más importantes en el orden militar y político del actual dictador de Sicilia: Imprenta y Librería de Gaspar y Roig, Editores; Garibaldi, G. (1861): Garibaldi: una autobiografía. Tr. Robson, William. Londres: Routledge, Warne \& Routledge; Pereda, S. (1895): Garibaldi, boceto histórico. Montevideo; Pereda, S. (1914, 1915.1916):
Garibaldi en el Uruguay, Montevideo: Ediciones el Siglo Ilustrado. Tomo I-III; Obras contemporáneas: Rama, C. (1968): Garibaldi y el Uruguay. Montevideo: Ediciones Nuestro Tiempo; Viotti, A. (1988): Garibaldi. Barcelona: Editorial Salvat; McLean, D. (1998): “Garibaldi in Uruguay: A Reputation Reconsidered" en The English Historical Review, Vol. 13 No. 451, pp.351-366. Oxford University Press; Arellano, J. (1999): Giuseppe Garibaldi, héroe de dos mundos en Nicaragua. Nicaragua: Publicidad Arellano Vásquez; Riall, L (2007): "Garibaldi: Invention of a hero". New Haven: Yale University Press; Cirocco, A. (2007): Garibaldi: Citizen of the world. Princeton: Princeton University Press; Ferrero, A. (2011): La presenza di Garibaldi in Peru. Lima: Universidad de Lima, entre otras.

[11] Dumas, Alexandre. Garibaldi e Montevideo. Milano: F. Manini, 1859. https://curiosity.lib.harvard. edu/latin-american-pamphlet-digital-collection/ catalog/43-990052684070203941; Garibaldi, Guiseppi. “Garibaldi: una autobiografía”. Tr. Robson, William. Londres, Routledge, Warne \& Routledge, 1861.

[12] Societá Italiana di Beneficenza “Garibaldi”. 1897. Statuto della Societá Italiana di Beneficenza “Garibaldi”. Istituita in Guayaquil il 24 giugno 1882. Guayaquil, Ecuador: Oficina Tipográfica Luque. En 1882 se estableció en Guayaquil (Ecuador) una Sociedad Italiana de Beneficencia en homenaje a la memoria del gran héroe de Caprera, se llama "Garibaldi", cuyo objeto es establecer la unión entre los miembros de la colonia, el fomento de la educación y socorrer a la desgracia y la indigencia de todos los italianos.

[13] Por referir algunos monumentos en homenaje a Garibaldi: Plaza Italia, Rosario, Argentina (1885); Plaza Italia, Buenos Aires, 1904; Salto, Uruguay 1950; 
Taganrog, Rusia, 2006; Niza, Francia, 2010. Bustos y estatuas: Villa Garibaldi, La Plata, Argentina, (1888); Patio externo del Hospital italiano Garibaldi; Plaza Garibaldi, Guayaquil; Budapest (2006); Washington Square Park (2005); Porto Alegre, Brasil (2007).

[14] Para seguir la historia de Italia puede verse Scalmatti, 2016.

[15] Miniserie brasilera As casa da sete mulheres, producida y proyectada por Rede Globo, 2003.

[16] Véase el performance festivo en alusión al 8 de mayo de 1860 en el puerto de Marsala, Italia). You tube. https://www.youtube.com/watch?v=_CkjIDgKD9M

[17] Cuando la popularidad de Garibaldi alcanzó su auge, la pintura se apoyará en las numerosas imágenes en forma de litografía y fotografía que le retrataban.

[18] Gerolamo, como pintor, contribuyó significativamente a plasmar el sentimiento retórico, nostálgico y épico del Risorgimento italiano. En telas de grandes dimensiones- en las que prima cierta meticulosidad cronaquística y documental, típica de aquel siglorepresentó hechos históricos y batallas vividos en su calidad de soldado.

[19] Los manuales de historia al uso hoy en día en las escuelas italianas, tanto en el Belpaese como las que se encuentran al extranjero, celebran aún este episodio con la misma atmósfera festiva, "perpetuando un cuento como argumento didáctico por generaciones" (Cfr. Insegni, 2010). 